\title{
Water Ecological Restoration Model Analysis on Chongqing's Polluted Reservoir
}

\author{
1,a XiangJie \\ ${ }^{1}$ Chongqing Institute of Water Resources, ChongQing Water Resources and electric engineering \\ college, Yongchuan, Chongqing 402160, China \\ a49935989@163.com
}

Keywords: Reservoir pollution, ecological restoration, model, design.

\begin{abstract}
The paper regards Chongqing's Nei Zikou Reservoir as the research object, conducts an establishment of ecological restoration model for this reservoir and sets up a concept model and mathematical model of ecological restoration, and the simulation value and measured value based on denitrification. The experimental result shows that it establishes a nitrogen cycle kinetic model and adopts the Runge-Kutta solution to solve this model. On the basis of the empirical value, the paper fits and revises this model. After calculating the efficiency coefficient of this model, it is about $93.2 \%$. the simulation sensitivity of this model is good.
\end{abstract}

\section{Introduction}

The damage of structure and function in our river ecosystem not only causes a great harm to biodiversity of water ecological system and sustainable utilization of water resource, but also brings a serious threat to drinking-water safety and health of human beings. Comparing with the developed countries, the theoretical research and practice in our river ecological restoration have a late start. Nowadays, with the sharp deterioration of water environment, our country also attaches importance to ecological restoration of damaged rivers and body of water. Though, a great number of researches on river ecological restoration have already done by domestic and overseas countries so far, in some concrete issues, such as what kind of theory should be an instruction to river ecological restoration, what kind of approach should be selected to realize, etc., there are also lack of the corresponding theory and research.

The protection of water ecosystem is a new task of water conservancy. Under the situation of implementing the current strictest water resource management system, in order to guard three red lines, especially reinforce protection of water ecosystem and restore target tasks, ensure the safety of residents' drinking-water, improve ecotope in the reservoir area and maintain better water quality in reservoir proposed by the third red line, it is crucial and urge to restore water ecosystem for large and medium-sized reservoirs within the area. The paper combines with work practice, adopts artificial wetlands system with different scales to dispose of rural domestic waste, applies ecological floating beds to purify polluted body of water within the Chongqing Nei Zikou Reservoir and improves water ecological environment within the entire reservoir area, so as to provide reference frame to protect ecotope in suburb water area. The paper takes advantage of ecological floating beds to dispose of Liwa River cityscape water, establishes damping fitted equation of phosphorus, sets up a nitrogen cycle kinetic model through Metlab programming, and simulated denitrification process by making use of Stella software to fit and revise the model. After calculating, the efficiency coefficient of this model is about $74.2 \%$. Simulation sensitivity of the model is ordinary.

\section{General Situation of the Reservoir and Pollution Status}

Nei Zikou Reservoir locates in Yinhu Village, Guangyang Town, Nanan District, Chongqng Municipality. Its river belongs to Xiaoxi River' s tributary of Changjiang River System. It is a small-sized hill reservoir that gives priority to water supply, irrigation and flood protection and gives consideration to comprehensive benefits of production and improving ecotope. The total storage of 
this reservoir is 1.5915 million $\mathrm{m} 3$. The designed output of annual supplying water is 2.09 million $\mathrm{m} 3$, while the practical output of annual supplying water is $80000 \mathrm{~m} 3$. The rainwater harvesting area is only $7500 \mathrm{~m} 3$. The borrowed (water diversion) rainwater harvesting area is $2.46 \mathrm{~km} 2$. Control catchment area of the damsite is $3.21 \mathrm{~km} 2$. The protected population of flood protection in this reservoir is 50 million. The cultivated land is $1000 \mathrm{mu}$. At present, water quality in Nei Zikou Reservoir is worse, especially for the water quality in front of the dam, where presents deep green and has bad water transparency. So it fails to meet the requirement of drinking-water source. The source of pollution mainly contains domestic wastewater, agricultural non-point source pollution, water and soil loss and aquaculture pollution in its surrounding crowd. The centralized drinking-water water plants in this reservoir need to adopt various purification treatment measures for surrounding water supply. It has an operating load and higher treatment cost.

\section{The Water Ecological Restoration Model}

The Conceptual Model:This experiment selects organic nitrogen, ammonia nitrogen and nitric nitrogen as state variable of an ecological kinetic model. Its existence forms can be divided into water (Org-N, NH4+-N, NO3" -N), matrix (N-gravel) and plant (N-Plants). Given that nitrogen conversion process mainly involves in mineralization, nitration, denitrification, plant absorption, microorganism assimilation, sediment, regeneration and plant corruption, etc. Its conceptual model is as shown in Figure 1:

The Mathematical Model:General expression of intrasystem mass balance in ecological floating beds is:

$Q_{i} C_{i}+V \sum_{k=1}^{n}\left(R_{c}\right) k=Q_{0} C_{0}+V \frac{d C_{0}}{d t}$

In the formula: Qi and Q0 分are inflow and outflow, respectively, m3/d. Ci and C0 are concentrations of inflow and outflow, respectively, $\mathrm{g} / \mathrm{m} 3$. V is the total volume of ecological floating bed system. $\mathrm{R}$ is a reaction rate of the volume g.m $3, \mathrm{~d}-1$, and $\mathrm{A}$ is the number of reaction and is dimensionless.



Figure 1 The Conceptual Model of Ecological Floating Beds

For nitrogen components with different forms in ecological floating beds, the above-mentioned formula represents its corresponding conversion process, respectively. For the nitrogen in organic nitrogen, ammonia and nitrate nitrogen and nitrogen in plants chosen in this simulation, its corresponding mass balance equations are ammonia and nitrogen(NH4+-N), respectively:

$$
\frac{d\left(N H_{4}^{+}-N\right)}{d t}=\frac{Q_{i}}{V}\left(N H_{4}^{+}-N\right)_{i}-\frac{Q_{0}}{V}\left(N H_{4}^{+}-N\right)_{o}-R_{p 1}-R_{n}-R_{M 1}+R_{m}
$$

In the formula: $\mathrm{NH}_{4}^{+}-\mathrm{N}$ are the concentrations of $\mathrm{NH}_{4}^{+}-\mathrm{N}$ in inflow and outflow, respectively, $\mathrm{g} / \mathrm{m} 3 ; \mathrm{Rn}$ is the rate of nitrification, $\mathrm{g} * \mathrm{~m} 3 \mathrm{~d}-1$; and $\mathrm{RMl}$ is nitrogen absorption rate in plants*m3d-1. Organic nitrogen $(\mathrm{ON})$ :

$\frac{d\left(O N_{0}\right)}{d t}=\frac{Q_{i}}{V} O N_{i}-\frac{Q_{0}}{V} O N_{o}+R_{p 1}+R_{p 2}+R_{d}-R_{m}-R_{s}$

In the formula, $\mathrm{ONi}$ and $\mathrm{ONo}$ are the concentrations of organic nitrogen in inflow and outflow, respectively, g/m3; Rp1 and Rp2 are microbial absorption rate of ammonia and nitrate, respectively 
$\mathrm{g}^{*} \mathrm{~m} 3 \mathrm{~d}-1$; $\mathrm{Rd}$ and $\mathrm{Rm}$ are the corruption rate of plants and mineralization rate of organic nitrogen, respectively, $g^{*} \mathrm{~m} 3 \mathrm{~d}-1$; Rs is the regeneration rate of ammonia, $\mathrm{g}^{*} \mathrm{~m} 3 \mathrm{~d}-1$.

The main process of mass balance for nitrate nitrogen $(\mathrm{NO} 3-\mathrm{N})$ includes denitrification plants and assimilation absorption of microorganism:

$$
\frac{d(\mathrm{NO} 3-\mathrm{N})}{d t}=\frac{Q_{i}}{V}(\mathrm{NO} 3-\mathrm{N})_{i}-\frac{Q_{0}}{V}(\mathrm{NO} 3-\mathrm{N})_{o}+R_{n}-R_{d n}-R_{p 2}-R_{M 2}
$$

In the formula, $(\mathrm{NO} 3-\mathrm{N}) \mathrm{i}$ and $(\mathrm{NO} 3-\mathrm{N}) 0$ are the concentrations of NO3-N in inflow and outflow, respectively, $\mathrm{g} / \mathrm{m} 3$; Rdn is the rate of denitrification, $\mathrm{g} * \mathrm{~m} 3 \mathrm{~d}-1$; RM2 is the absorption rate of nitrate in plants, g*m3d-1.

Nitrogen mass balance in matrix is mainly the process of sediment and regeneration for ammonia and nitrogen.

$\frac{d\left(\mathrm{~N}_{\mathrm{aggr}}\right)}{d t}=R_{s}-R_{r}$

Mass balance in organic nitrogen in plants is mainly affected by absorption of nitrate and ammonia and corruption of plants:

$\frac{d\left(\mathrm{~N}_{\text {plantr }}\right)}{d t}=R_{M 1}+R_{M 2}-R_{d}$

Mass balance equations from (1) to (6) involve in every reaction process. Its reaction rate should be described by adopting different reaction kinetics equations. Mineralization (Am): mineralization of organic nitrogen is realized by translating organic nitrogen into ammonia through biodegradation. The mineralization rate adopts first-order kinetics of organic nitrogen concentration to simulate. Nitration (An): Nitration considers suspension biomass and activities of biological film in the system. It thinks that biomass of biological film is nitrosomonas, attaching to the surface of matrix and the root plant zone. Nitration of suspension bacteria is simulated with the Monod model. Nitration of biological film uses the biological film model established by Polprasert and Agarwalla. The calculation of nitrification rate (An) adopts the nitration model united by the above-mentioned models.

Denitrification (And): thinks that activities of biological film biomass affect the denitrification with the same degree. The calculation of nitration adopts the united model of the Arrhenius kinetic model and the above-mentioned biological film model. Absorption ammonia of microorganism (Apl): autotrophic bacteria absorbs ammonia nitrogen or nitrate nitrogen, but it will give priority to ammonia. For the purpose of simulating the absorption rate of ammonia for microorganism, it is supposed that it will be absorbed as long as it exists in the system. Microorganisms of suspension and biological film are completely absorbed by ammonia. The absorption rate Apl adopts the united model of the Monod kinetic model and the above-mentioned biological film model.

Absorption of solid nitrogen by microorganism (Ap2): The model supposes that it starts to consume nitrate after the microorganism consumes ammonia completely in the system. Absorption rate Ap2 also adopts the united model of the Monod kinetic model and biological film model. The absorption of ammonia by plants (AMI): The absorption rate of ammonia by plants adopts first-order kinetics to simulate. Moreover, the absorptive amount is proportional with the concentration of inorganic nitrogen. It should adopt the formula mentioned in the reference [51] to calculate AMI. The absorption of nitrate nitrogen by plants (AM2): It is similar to the absorption of ammonia by plants. Plant corruption (Ad): It supposes that corruption rate submits to first-order kinetic equation.

Model Solution and Parameter Optimization:The model solution applies for-stage Runge-Kutta solution and is realized by adopting MATLAB independent programming. Based on the empirical value of parameters, the paper fits and revises parameters for the model. Most of parameters can be in the range of empirical value after fitting. The Table 1 lists parts of model parameters and their corresponding corrected value. 
Table 1 Parts of Parameters and Corrected Values

\begin{tabular}{l|l|l|l}
\hline Parameter & Description & \multicolumn{1}{|c}{ Reference Value } & Corrected Value \\
\hline Df & $\begin{array}{l}\text { Diffusion coefficient in } \\
\text { biological film, m2/d }\end{array}$ & $5.26 \times 10-5$ & $5.26 \times 10-5$ \\
\hline Lf & Thickness of biological film, m & $(1.46 \sim 1.62) \times 10-3$ & $1.62 \times 10-3$ \\
\hline Dr2s & $\begin{array}{l}\text { In 25 } \\
\text { denitrification, d-1 constant of }\end{array}$ & $0 \sim 1.0$ & 0.98 \\
\hline rreg & $\begin{array}{l}\text { Regeneration rate constant of } \\
\text { ammonia nitrogen, d-1 }\end{array}$ & 0.085 & 0.085 \\
\hline rmin & Mineralization rate, d-1 & $0.0005-0.143$ & 0.1 \\
\hline a & Absorption coefficient & $0.0008-0.012$ & 0.009 \\
\hline a S1 & $\begin{array}{l}\text { Area/volume of plants , } \\
\text { biological film, m2/m3 }\end{array}$ & $1.67-1.93$ & 1.8 \\
\hline
\end{tabular}

\section{Contrastive Analysis on the Simulated Value and Measured Value}

Based on denitrification, the paper analyzes the simulated value and measured value. The Figure 2 and Figure 4 contrast the measured value and simulated value of organic nitrogen, ammonia nitrogen and concentration of solid nitrogen in inflow. It shows that the model basically can reflect the change of variation tendency to three kinds of main nitrogen forms.

There is a difference between the simulated value and measured value. The paper adopts the model to calculate the efficiency coefficient of the model. The value of efficiency coefficient is more closely to 1 . It indicates that the measured value and simulated value are closer.

$$
R=\left[1-\frac{\sum_{i=1}^{m}\left(Q_{s, t}-Q_{m, i}\right) 2}{\sum_{i=1}^{m}\left(Q_{s, t}-Q_{s, \text { 均 }}\right) 2}\right] \times 100 \%
$$

In the formula: Qs,i, Qm,I and Qs are the measured flow value, simulated flow value and actual measured value in the ith, respectively.
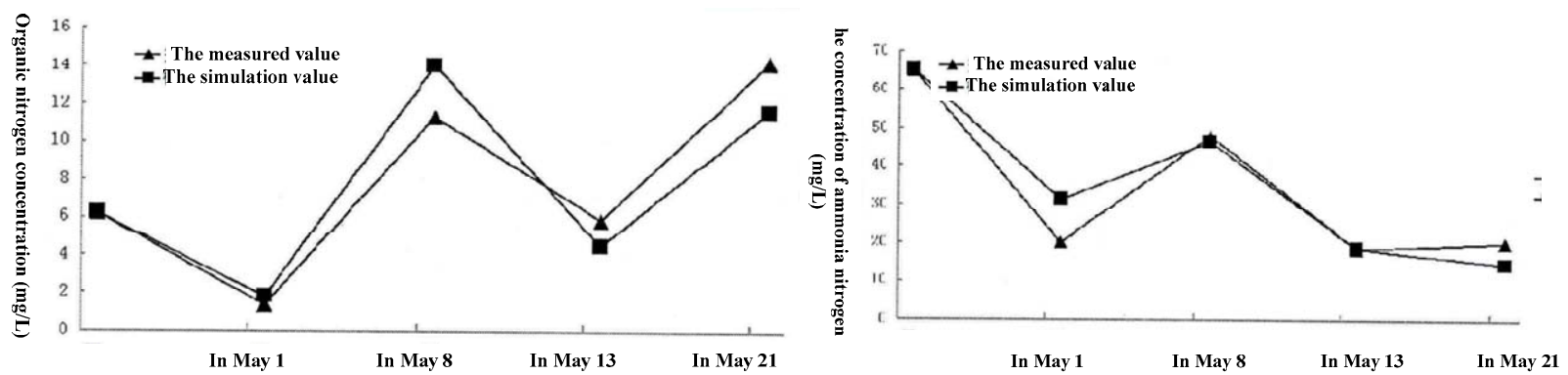

Figure 2 Comparison of Organic Nitrogen between the Measured Value and Simulated Value Figure 3 Comparison of Ammonia Nitrogen between the Measured Value and Simulated Value



Figure 4 Comparison of N03-N between the Measured Value and Simulated Value 
After calculating, the efficiency coefficient of the model is $93.2 \%$. It has a good imitative effect, but also has a certain deviation. The mainly reasons include the following aspects:

(1) When fitting parameters, the limitation of adoptive empirical value is likely to give rise to deviation to results. Reference values may apply to a controlled condition, while the in practical engineering application, the condition may change at any time. Therefore, in order to obtain comparatively correct parameters, it needs to conduct a test on biology, chemistry and physics, and knows about nature and reactivity of microorganism under the specified conditions. In this way, comparatively correct model parameters that fit for specific sites can be obtained.

(2) The measurement of this measured value has a certain error and has a fewer data volumes. it may result in smaller $\mathrm{R}$ value and lower efficiency coefficient.

\section{Conclusions}

Ecological restoration is an effective measure to improve the eutrophication of lakes and reservoirs. By researching the mechanism of ecological restoration, the paper establishes the mathematical model of water ecological restoration of Chongqing Reservoir. It brings ecological kinetics in the model to control the growth kinetic model, which is applied to the practical study and has gained a better effect. Research results show that the established ecological restoration model can reflect the variation of materials and algous growth rhythm. The mechanism of establishing this model is reliable and reasonable. It can provide powerful support for the research on pollution mechanism of Chongqing Reservoir.

(The fund number: Yushui science 201306; The approval of the project unit: Chongqing City Water Conservancy Bureau;Project Name: Chongqing city drinking water source (reservoir) plant configuration specification of water resources conservation and water ecological restoration project)

\section{References}

[1] Wang Yonggui, The Shellfish Ecological Restoration Model and Application in Lakes and Reservoirs of Eutrophication[J]. Journal of Hydrophytes, 2010, 17(3): 5-7.

[2] Zhang Shaohao, Preliminary Study on Controlling Water Quality by Taking Advantage of Hyriopsis Cumingii, Journal of Aquatic Organism, 2007, 31(5): 760-762.

[3] Peng Hong, Numerical Modeling of Ecological Restoration in Water Quality of Shallow Water, Water Panning and Design, 2007, 1: 57-50.

[4] Liu Yusheng, The influence of Illumination, Temperature and Nutritive Salt on the Growth of Microcystis in the Dian Lake [J]. Environmental Sciences, 2010, 12:7-11.

[5] Li Xin and Wei Chunyu, Metropolis Green Island-Imagination of a Kind of Urban Organic Symbiosis Model [J], Chinese and Overseas Architecture, 2010(5): 85-89.

[6] Ha Fei and Jin Pengfei, Ecological Restoration Technology of Riverway and Its Practice in Shanghai Municipality [J]. Water-Saving Irrigation, 2009, 7:46-49.

[7] Song Xinshan, et al., The Design Model Research on Constructing Hydraulics Parameters of Wetland System [J]. Environmental Sciences and Technology, 2009, 23(3): 35-38.

[8] Zheng Huanchun, Functions of Microorganism on Bioremediation in Eutrophic Water [J]. China Journal of Eco-Agriculture, 2009, 17(1): 197-201.

[9] Liu Qing and Yuan Guanjie, Application of Microorganism Purifier in Flow Water Body Remediation [J], Journal of Huazhong University of Science and Technology, 2008, 25(1): 82-84. 